\title{
Investigation of Epistasis Between the Serotonin Transporter and Norepinephrine Transporter Genes in Anorexia Nervosa
}

\author{
Ruth E Urwin ${ }^{*, 1,5}$, Bruce H Bennetts ${ }^{2,6}$, Bridget Wilcken ${ }^{3,6}$, Pierre JV Beumont ${ }^{4,5}$, Janice D Russell ${ }^{5}$, Kenneth \\ P Nunn ${ }^{1,5}$ \\ 'Department of Psychological Medicine, The Children's Hospital at Westmead, Westmead, NSW, Australia; ${ }^{2}$ Department of Molecular Genetics, \\ The Children's Hospital at Westmead, Westmead, NSW, Australia; ${ }^{3}$ Department of Biochemical Genetics and Newborn Screening, The \\ Children's Hospital at Westmead, Westmead, NSW, Australia; ${ }^{4}$ Department of Psychiatry, Royal Prince Alfred Hospital, Camperdown, NSW, \\ Australia; ${ }^{5}$ Discipline of Psychological Medicine, University of Sydney, NSW, Australia; ${ }^{6}$ Discipline of Paediatrics and Child Health, University of \\ Sydney, NSW, Australia
}

\begin{abstract}
Weight-restored patients with anorexia nervosa (AN) respond favorably to the selective serotonin reuptake inhibitor fluoxetine, which justifies association studies of the serotonin transporter gene (SLC6A4, alias SERT) and AN. Case-control studies suggest that the least transcriptionally active allele of the SERT gene promoter polymorphism (5-HTTLPR) has an increased frequency in AN patients. However, this finding was not replicated with 55 trios (AN child + parents) and the transmission disequilibrium test (TDT). To clarify the role of the 5-HTTLPR in susceptibility to AN, we used the TDT and 106 Australian trios to provide 93\% power to detect a genotypic relative risk (GRR) of 2.0. Our results were negative for this GRR (McNemar's $\chi^{2}=0.01, \mathrm{df}=1, p=0.921$, odds ratio $1.0,95 \% \mathrm{Cl}$ 0.7-1.5). Additionally, we found no association with AN females, AN subtype, age at onset, or minimum BMI. We then performed the first reported investigation of epistasis between the SERT gene and norepinephrine transporter gene (SLC6A2, alias NET) in AN, as an earlier study suggested that atypical AN responds to the dual serotonin-norepinephrine reuptake inhibitor venlafaxine. We observed no epistasis between the 5-HTTLPR and a polymorphism within the NET gene promoter polymorphic region $(\mathrm{NETpPR})\left(\chi^{2}=0.48, \mathrm{df}=1\right.$, $p=0.490)$. Although 5 -HTTLPR modulates serotonin reuptake by the serotonin transporter, our analyses provide no evidence that susceptibility to AN is modified by 5-HTTLPR alone, nor in concert with as yet undetermined functional effects of the NETpPR polymorphism.

Neuropsychopharmacology (2003) 28, I 35 I-1355, advance online publication, I 4 May 2003; doi: I 0. I 038/sj.npp. I 300204
\end{abstract}

Keywords: genetic epistasis; eating disorders; anorexia nervosa; norepinephrine; serotonin; carrier proteins

\section{INTRODUCTION}

DSM-IV (American Psychiatric Association, 1994) anorexia nervosa (AN) is diagnosed when body weight remains below $85 \%$ of normal, and there is an intense fear of gaining weight, a disturbed perception of one's shape and/or weight, and amenorrhea (in females). Weight is controlled by food restriction (AN-R) or purging (AN-BP). Atypical AN meets all AN-R or AN-BP diagnostic criteria except that weight remains just above the diagnostic threshold or amenorrhea is absent. Serotonergic dysfunction is implicated in AN pathophysiology (Brewerton and Jimerson, 1996) as long-

*Correspondence: RE Urwin, Department of Psychological Medicine, The Children's Hospital at Westmead, Locked Bag 4001, Westmead, NSW 2145, Australia, Tel: +6I 29845 2005, Fax: +6I 298452009 , E-mail: RuthU@chw.edu.au

Received 28 November 2002; revised 18 February 2003; accepted II March 2003

Online publication: 27 March 2003 at http://www.acnp.org/citations/ Npp032703434/default.pdf term, weight-restored patients have elevated CSF levels of the serotonin (5-HT) metabolite 5-hydroxyindoleacetic acid (Kaye et al, 1991a). Additionally, the selective 5-HT reuptake inhibitor (SSRI) fluoxetine targeted at the 5-HT transporter may be clinically useful in weight-restored AN patients (Kaye et al, 1991b; Kaye et al, 2001). These observations, and twin and family data suggesting a genetic component in AN (Holland et al, 1988; Strober et al, 2000), justify association studies of AN and the 5-HT transporter gene (SLC6A4, alias SERT). Within the SERT gene promoter lies the 5-HT transporter-linked polymorphic region (5HTTLPR). 5-HTTLPR is a functional polymorphism with two common alleles. The short $(S)$ allele consists of 14 repeats of a 20-23-bp sequence. The long $(L)$ allele consists of 16 repeats having transcriptional activity triple that of the $S$ allele (Heils et al, 1996). The $L / L$ genotype doubles 5-HT transporter expression relative to genotypes carrying one or two $S$ alleles (Lesch et al, 1996) justifying two genotype groups $(L / L$ vs $S / S+S / L)$ for association studies. Rare variants include a 15-repeat allele (Nakamura et al, 2000) 
with undetermined effect on transcription. Case-control studies (Di Bella et al, 2000; Sundaramurthy et al, 2000; Fumeron et al, 2001) demonstrate a trend towards increased frequency of the $S$ allele, and $S / S$ or $S / L$ genotypes in AN patients, reaching statistical significance for AN-BP patients once (Di Bella et al, 2000) $(p=0.020$, odds ratio $1.9,95 \% \mathrm{CI}$ $1.1-3.1$ ). However, the one family-based study (Hinney et al, 1997), which used the transmission disequilibrium test (TDT) (Spielman et al, 1993) and 55 trios (AN child+ parents), provided no evidence for preferential transmission of the $S$ allele as $52 S / L$ parents transmitted $27 S$ and $25 L$ alleles to AN children $(p=0.90)$. Disagreement between the case-control and family-based findings may involve population stratification bias in the case-control studies. However, if 5-HTTLPR has little involvement in AN, a false negative result in the family-based study is not ruled out as it has only $67 \%$ power to detect a susceptibility allele with a genotypic relative risk (GRR) of 2.0.

Data also point to noradrenergic dysregulation in $\mathrm{AN}$. Long-term, weight-restored AN patients have low norepinephrine levels in blood and CSF (Kaye et al, 1985; Pirke et al, 1992). Furthermore, venlafaxine, which blocks reuptake by 5 -HT and norepinephrine transporters, may be useful for treating atypical AN (Ricca et al, 1999). Additionally, we recently demonstrated strong association between a polymorphism in the norepinephrine transporter gene (SLC6A2, alias NET) promoter polymorphic region (NETpPR) and AN-R (Urwin et al, 2002). Although a gene's independent contribution to disease may avoid detection, its involvement in disease susceptibility may become apparent through epistasis (gene-gene interaction) (Ritchie et al, 2001; Culverhouse et al, 2002). It is important to know whether susceptibility to develop AN increases when DNA sequence variations in different genes occur simultaneously. We hypothesized that there is epistasis between the SERT and NET genes in $\mathrm{AN}$, and through investigating this hypothesis report the first investigation of epistasis between these genes. Additionally, to clarify whether 5-HTTLPR is independently involved in AN we employ the TDT and 106 Australian trios to provide 80 and $93 \%$ power to detect GRRs of 1.75 and 2, respectively.

\section{MATERIALS AND METHODS}

\section{Subjects}

Our 106 unrelated trios (102 Caucasian, four East Asian) were recruited from Sydney and Melbourne (Australia) and included the 101 trios reported in Urwin et al (2002), in which we found AN-R to be associated with the NETPPR L4 allele and L4/L4 genotype, plus five trios recruited later. Each trio consisted of one DSM-IV AN patient plus both biological parents. Families were excluded if both parents were unavailable for testing. Ethics approval had been gained from the appropriate institutional Committees on Human Experimentation in accord with the Helsinki Declaration of 1975. All participants gave written informed consent (parents signed for children aged under 14 years). Patients were consecutive consenting inpatients $(n=98)$ or outpatients $(n=8)$ admitted for treatment of $\mathrm{AN}$ and all currently fulfilled/had previously fulfilled DSM-IV AN criteria, except presence of amenorrhea was waived for males and prepubertal females. Diagnosis of AN (including $\mathrm{AN}-\mathrm{R}$ and $\mathrm{AN}-\mathrm{BP}$ ) was made blind to genotype and involved longitudinal assessment and case note searches. Diagnosis was made by eating disorder specialists, and confirmed with $95 \%$ consensus by one of three psychiatrists (KPN, JDR, PJVB) after a personal interview and examination of collated data. KPN reviewed the case notes to confirm/disconfirm the diagnosis where diagnostic ambiguity existed. Ages and BMI were recorded during assessment. BMI was determined from weight and height measured by hospital staff, the DSM-IV AN weight criterion being based on the minimum BMI recorded. At minimum BMI, all AN patients aged 11-15 years weighed less than or equal to their age and sex-specific 5 th percentile BMI cutoff as determined in an Australian population study (Harvey and Althaus, 1993). Above 15 years of age a BMI of 17.5 was the upper limit (WHO, 1992). There were 101 female (87 $\mathrm{AN}-\mathrm{R}, 14 \mathrm{AN}-\mathrm{BP}$ ) and five male patients (three AN-R, two AN-BP). Of the 101 females, 28 were aged under 15 years (mean age $13.60 \pm 1.25$ years) at their minimum BMI (mean minimum BMI $14.20 \pm 1.61)$ reached at a mean of $0.92 \pm 0.58$ years after onset of $\mathrm{AN}$, and 73 were aged 15 years and over (mean age $18.18 \pm 3.46$ years) at minimum BMI (mean minimum BMI $14.70 \pm 1.75$ ) reached at a mean of $2.38 \pm 2.24$ years after onset of AN. The five males were aged $13.50,13.70,14.70,18.00$, and 22.40 years at minimum BMI values of $14.54,15.08,15.56,12.64$, and 15.43, respectively, reached $2.50,0.60,0.30,2.00$, and 2.40 years after onset of $\mathrm{AN}$, respectively.

\section{Molecular Genetic Methods}

EDTA venous blood $(10 \mathrm{ml})$ was collected from patients and parents. Genomic DNA was extracted from the blood using standard methods (Miller et al, 1988). 5-HTTLPR was PCRamplified using previously published primer sequences (Heils et al, 1996): forward primer stpr5 5'GGCGTTGCCGCTCTGAATGC (positions -1416 to -1397 ) and reverse primer stpr3 5'-GAGGGACTGAGCTGGACAACCAC (positions -910 to -888 ). Base numbering relates to the start site of the Heils et al (1996) sequence. Amplification conditions from Heils et al (1996) were modified as follows. PCR reactions were performed in $10 \mu \mathrm{l}$ volumes containing $10 \mathrm{mM}$ Tris $-\mathrm{HCl} \mathrm{pH} 8.3,50 \mathrm{mM} \mathrm{KCl}$, $1.5 \mathrm{mM} \mathrm{MgCl}_{2}, 0.5 \mu \mathrm{M}$ of each primer, $200 \mu \mathrm{M}$ of each dNTP (7-deaza-dGTP replaced all dGTP), 5\% dimethyl sulfoxide, $0.25 \mathrm{U}$ of Ampli-Taq Gold (Applied Biosystems, Foster City, CA, USA), and $50 \mathrm{ng}$ DNA template. The GeneAmp PCR System 9700 (Applied Biosystems) was used for thermal cycling: $95^{\circ} \mathrm{C}$ for $10 \mathrm{~min} ; 30$ cycles of $95^{\circ} \mathrm{C}$ for $30 \mathrm{~s}, 67-$ $52.5^{\circ} \mathrm{C}$ for $30 \mathrm{~s}$ (decreased by $0.5^{\circ} \mathrm{C} /$ cycle over the 30 cycles from 67 to $52.5^{\circ} \mathrm{C}$ ), $72^{\circ} \mathrm{C}$ for $40 \mathrm{~s} ; 10$ cycles of $95^{\circ} \mathrm{C}$ for $30 \mathrm{~s}$, $52^{\circ} \mathrm{C}$ for $30 \mathrm{~s}, 72^{\circ} \mathrm{C}$ for $40 \mathrm{~s}$; and finally $72^{\circ} \mathrm{C}$ for $10 \mathrm{~min}$. PCR products were separated by size on $8 \%$ polyacrylamide, followed by silver staining using a modification of the Merril et al (1981) method (ie $5 \mathrm{~min} 10 \%$ ethanol, $3 \mathrm{~min} 3 \%$ nitric acid, two water washes, $15 \mathrm{~min} 0.1 \%$ silver nitrate, one water wash, incubation in $50 \mathrm{ml} \mathrm{3 \%} \mathrm{NaOH}$ containing $40 \mu \mathrm{l}$ $37 \%$ formaldehyde until desired staining was achieved, two water washes, $5 \mathrm{~min} 3 \%$ acetic acid, one water wash). Direct DNA sequencing of a 16-repeat homozygote PCR product using the ABI Prism Big Dye Terminator Ready Reaction Kit 
(Applied Biosystems) and the ABI PRISM 377 DNA Sequencer (Applied Biosystems) confirmed amplification of the correct DNA sequence. A known 14-repeat/16-repeat heterozygote and DNA standard were used to identify 5HTTLPR variants.

The 343-bp NETpPR within the NET gene promoter region includes six AAGG repeat islands (AAGG1-AAGG6). The methodology to detect a 4-bp deletion(S4)/insertion(L4) polymorphism in AAGG4 is described in Urwin et al (2002), in which AN-R was associated with L4 and the L4/L4 genotype. NETpPR genotyping data for 90 AN-R trios in the current study (87 trios genotyped for Urwin et al (2002) plus three trios recruited and genotyped later) were (transmitted: nontransmitted) alleles L4 (145:123), S4 (35:57) and genotypes L4/L4 (58:41), S4/L4 (29:41), S4/ S4 $(3: 8)$. (NB. nontransmitted genotype $=$ two nontransmitted alleles). L4/L4 was preferentially transmitted to AN$\mathrm{R}$ children $\left(\chi^{2}\right.$ for trend $=7.23, \mathrm{df}=1, p=0.0072 ; \mathrm{L} 4 / \mathrm{L} 4$ vs S4/L4+ S4/S4: $\chi^{2}=6.49, \mathrm{df}=1, p=0.0109 ; \mathrm{L} 4 / \mathrm{L} 4$ vs S4/L4: $\left.\chi^{2}=4.83, \quad \mathrm{df}=1, \quad p=0.0279\right)$, justifying forming two NETpPR genotype groups for an epistasis study: L4/L4 vs S4/L4+S4/S4. NETPPR data for $16 \mathrm{AN}-\mathrm{BP}$ trios in the current study (14 trios genotyped for Urwin et al (2002) plus two trios recruited and genotyped later) were (transmitted:nontransmitted) alleles L4 (22:28), S4 $(10: 4)$ and genotypes L4/L4 (7:12), S4/L4 (8:4), S4/S4 $(1: 0)$ suggesting preferential transmission of $\mathrm{S} 4$. Accordingly, AN-R and AN-BP data have been analyzed together and separately in the current report.

\section{Statistical Analysis}

The TDT detected preferential transmission of 5-HTTLPR alleles from heterozygous parents and was performed using McNemar's $\chi^{2}$ test. Hardy-Weinberg equilibrium and epistasis were assessed with $\chi^{2}$ or Fisher's exact tests. GraphPad InStat V3.05 was used for the unpaired $t$-test. Power calculations were performed using published equations (Risch and Merikangas, 1996), assuming allele frequencies of $L=0.57$ and $S=0.43$ observed in an Australian population study (Jorm et al, 1998). The required significance level was set at 0.05 . Two-sided $p$-values were used.

\section{RESULTS}

The 5-HTTLPR genotyping data reported here includes those from the same 101 trios involved in Urwin et al (2002) in which their NETpPR genotypes were determined. The NETpPR genotype of each AN child in these 101 trios is used in the epistasis analysis below. Additionally, 5HTTLPR and NETPPR genotyping data from five trios recruited after Urwin et al (2002) are also analyzed here (ie a total of 106 trios).

In the 5-HTTLPR association study, there were 106 trios. As the rare 15-repeat allele was detected in only four parents (two East Asian, two Caucasian), it was firstly analyzed as an $S$ allele (data reported here) and then as an $L$ allele (data not shown), with no change in the statistical significance. Genotype frequencies were in Hardy-Weinberg equilibrium (parents: $\chi^{2}=0.44, \mathrm{df}=1, p=0.508$; AN children: $\chi^{2}=0.64$,
Table I Epistatic Interaction Analysis: 5-HTTLPR TDT Data from I06 AN Family Trios Stratified by (Conditioned on) AN Child's NETpPR Genotype

\begin{tabular}{|c|c|c|c|c|c|}
\hline \multirow{2}{*}{$\begin{array}{l}\text { Child's } \\
\text { NETpPR } \\
\text { genotype }\end{array}$} & \multirow[b]{2}{*}{$\begin{array}{l}\text { Number } \\
\text { of trios }\end{array}$} & \multicolumn{2}{|c|}{$\begin{array}{l}\text { Allele transmitted from } \\
\text { 5-HTTLPR S/L parents }\end{array}$} & \multirow{2}{*}{$\begin{array}{c}\text { TDT } \\
\text { McNemar's } \\
\chi^{2}\end{array}$} & \multirow[b]{2}{*}{$P$} \\
\hline & & $s$ & $L$ & & \\
\hline L4/L4 & 65 & 26 & 30 & 0.29 & $0.593 *$ \\
\hline S4/L4+S4/S4 & 41 & 24 & 21 & 0.20 & $0.655 *$ \\
\hline Combined & 106 & 50 & 51 & & \\
\hline
\end{tabular}

*Not significant

$\mathrm{df}=1, \quad p=0.423)$. Alleles were (transmitted: nontransmitted) $S(102: 103)$ and $L(110: 109)$, and genotypes were (transmitted : nontransmitted) $S / S(22: 26), S / L$ (57:50), and $L / L$ (27:30). The TDT ('Combined' data from Table 1) provided no evidence of preferential transmission of either allele as $S / L$ parents transmitted $50 S$ and $51 L$ alleles (McNemar's $\chi^{2}=0.01, \mathrm{df}=1, p=0.921$, odds ratio $1.0,95 \%$ CI $0.7-1.5)$. This finding was supported by the haplotypebased haplotype relative risk (HHRR) test (Terwilliger and Ott, 1992) as neither allele was significantly more common in patients than in parents $\left(\chi^{2}=0.01, \mathrm{df}=1, p=0.923\right.$, odds ratio $1.0,95 \%$ CI $0.7-1.4$ ), and through the haplotype relative risk (HRR) test (Falk and Rubinstein, 1987) as neither the $L / L$ nor $S / S+S / L$ genotype group was significantly more common in patients than in nontransmitted genotypes $\left(\chi^{2}=0.22, \mathrm{df}=1, p=0.642\right.$, odds ratio $1.2,95 \%$ CI $0.6-2.1)$.

Additionally (data not shown), the TDT did not demonstrate preferential transmission of either allele in 101 trios in which the affected child was female (F-AN trios) (McNemar's $\chi^{2}=0.01, \mathrm{df}=1, p=0.919$, odds ratio $1.0,95 \%$ CI $0.7-1.6$ ), in $90 \mathrm{AN}-\mathrm{R}$ trios (McNemar's $\chi^{2}=0.05, \mathrm{df}=1$, $p=0.829$, odds ratio $1.0,95 \%$ CI $0.6-1.5)$, or in 16 AN-BP trios (McNemar's $\chi^{2}=0.07, \mathrm{df}=1, p=0.796$, odds ratio 1.1 , 95\% CI 0.4-3.7). The unpaired $t$-test (data not shown) showed no difference between genotype groups ( $L / L$ vs $S /$ $S+S / L)$ in the 106 trios for age of onset $(t=1.238, \mathrm{df}=104$, $p=0.219)$ or minimum BMI $(t=1.187, \mathrm{df}=104, p=0.238)$, in F-AN trios (age of onset: $t=1.177, \mathrm{df}=99, p=0.242$; minimum BMI: $t=0.906, \mathrm{df}=99, p=0.367)$, in AN-R trios (age of onset: $t=0.895$, $\mathrm{df}=88, p=0.373$; minimum BMI: $t=0.846, \mathrm{df}=88, p=0.400$ ), or in AN-BP trios (age of onset: $t=0.250, \mathrm{df}=14, p=0.806$; minimum BMI: $t=1.027$, $\mathrm{df}=14, p=0.322$ ). Allele transmissions from $S / L$ parents in the current and German study (Hinney et al, 1997) were homogeneous $\left(\chi^{2}=0.08, p=0.777\right)$, justifying combining the results (total $=161$ trios) to allow 80 and $99 \%$ power to detect a GRR of 1.6 and 2.0, respectively. Of $153 \mathrm{~S} / \mathrm{L}$ parents in 161 trios, 77 transmitted $S$ and 76 transmitted $L$ (McNemar's $\chi^{2}=0.01, \mathrm{df}=1, p=0.936$, odds ratio 1.0 , 95\% CI $0.7-1.4$ ), clearly providing no evidence of association with a 5-HTTLPR allele at these GRRs.

We then investigated possible epistatic interaction between the 5-HTTLPR and the NETPPR polymorphism by stratifying the 5-HTTLPR TDT data based on the AN child's NETpPR genotype (justified in Molecular Genetic 
Methods) to form a $2 \times 2$ contingency table (Table 1 ). The top stratum consisted of 5-HTTLPR TDT data from parents of 65 NETpPR-L4/L4 children. The bottom stratum was composed of 5-HTTLPR TDT data from parents of 41 NETpPR-S4/L4 or S4/S4 children. TDT analysis of each stratum provided no evidence of either 5-HTTLPR allele being preferentially transmitted when conditioned on the child's NETpPR genotype. Comparing the strata was not statistically significant $\left(\chi^{2}=0.48, \mathrm{df}=1, p=0.490\right)$, suggesting no interaction between the 5-HTTLPR and NETPPR polymorphisms in AN. The findings were similar (data not shown) for the F-AN trio data $\left(\chi^{2}=0.53, \mathrm{df}=1, p=0.465\right)$, AN-R trio data $\left(\chi^{2}=0.0002, \mathrm{df}=1, p=0.989\right)$ and AN-BP trio data (Fisher's exact test $p=0.442$ ).

\section{DISCUSSION}

We feel that our results demonstrate that there is no association between 5-HTTLPR and AN in Australians (unless AN is weakly associated with a 5-HTTLPR allele). This finding is similar to results from Germany (Hinney et al, 1997), although our study has greater power due to almost double the sample size. If 5-HTTLPR predisposes an individual to developing $\mathrm{AN}$, then its independent effect is extremely small and possibly clinically irrelevant. It must be made clear, however, that negative association of AN with 5HTTLPR does not necessarily extend to the entire SERT gene given the distance from 5-HTTLPR to the intron 2 variable number of tandem repeats (VNTR) polymorphism and $3^{\prime}$ UTR. There may be other functional polymorphisms in the SERT gene involved in AN that are not in linkage disequilibrium with 5-HTTLPR. A lack of linkage disequilibrium between the ends of a gene is demonstrated in the dopamine transporter gene (Greenwood et al, 2002) and dopamine 2 receptor (DRD2) gene (Gelernter et al, 1998). Recently, Kim et al (2002) also reported that autistic disorder may have stronger association at locations other than at 5-HTTLPR. As intron 2 VNTR is reported to be a functional polymorphism (Lovejoy et al, 2003), studies of intron 2 VNTR and haplotypes including 5-HTTLPR and intron 2 VNTR (and other polymorphisms contributing to haplotype blocks in the SERT gene) are the minimum required to exclude major effects at this gene in $\mathrm{AN}$ (although major effects in complex genetic disorders are unlikely). We also did not observe the increased $S$ allele frequency seen in case-control study AN patients possibly due to clinical and/or genetic heterogeneity, variability of linkage disequilibrium between the 5-HTTLPR and another susceptibility allele in different samples, or population stratification affecting the case-control findings. Supporting population stratification, $S$ allele frequencies in case-control study controls (Di Bella et al, 2000; Sundaramurthy et al, 2000; Fumeron et al, 2001) and in the nontransmitted alleles reported here range from 0.36 to $0.49\left(\chi^{2}=9.48, \mathrm{df}=3\right.$, $p=0.024$ ) and $S$ allele frequencies range from 0.11 to 0.70 , worldwide (Gelernter et al, 1999). We used the TDT to diminish problems due to population stratification. In the TDT, the transmitted (case) and nontransmitted (control) alleles form the parent's genotype and hence are ethnically matched. Interestingly, AN patients have similar $S$ allele frequencies across both the current and case-control studies: $0.48-0.51\left(\chi^{2}=0.60, \mathrm{df}=3, p=0.895\right)$. We also found no association between the $S$ allele and AN-BP reported by Di Bella et al (2000), although our 16 AN-BP trios provide low power for this observation. Additionally we found no association between 5-HTTLPR and AN females, AN subtype, age at onset, or minimum BMI.

Epistatic interaction between 5-HTTLPR and NETpPR polymorphism was not evident in our AN sample as alleles transmitted from 5-HTTLPR $S / L$ parents were not conditional on the NETPPR genotypes of their children. Our results cannot be influenced by linkage disequilibrium as the SERT and NET genes are on different chromosomes (Brüss et al, 1993; Ramamoorthy et al, 1993). However, our findings do not necessarily extend to the entire SERT and NET genes.

In conclusion, although 5-HTTLPR affects reuptake of 5HT by the 5-HT transporter, we provide no evidence that susceptibility to AN is modified by this mechanism alone, nor in concert with unknown functional mechanisms modified by the NETPPR polymorphism. However, we cannot exclude the possibility of a relation between 5HTTLPR (and other SERT gene variation) and response to SSRIs in AN.

\section{ACKNOWLEDGEMENTS}

This study was supported by Children's Hospital Fund Small grant SGS9808, donations from Anne Shaw Kennedy, and the Estate of the Late Charlotte Ross. We thank Drs Wiley and Carpenter for the use of their laboratories, individuals recruiting subjects at 'Footprints of Angels', Northside Clinic, Royal Prince Alfred Hospital, The Children's Hospital at Westmead, Wesley Private Hospital, and Westmead Hospital, and especially the families for participating in the study.

\section{REFERENCES}

American Psychiatric Association (1994). Diagnostic and Statistical Manual of Mental Disorders, 4th edn American Psychiatric Press: Washington, DC.

Brewerton TD, Jimerson DC (1996). Studies of serotonin function in anorexia nervosa. Psychiatry Res 62: 31-42.

Brüss M, Kunz J, Lingen B, Bönisch H (1993). Chromosomal mapping of the human gene for the tricyclic antidepressantsensitive noradrenaline transporter. Hum Genet 91: 278-280.

Culverhouse R, Suarez BK, Lin J, Reich T (2002). A perspective on epistasis: limits of models displaying no main effect. Am J Hum Genet 70: 461-471.

Di Bella D, Catalano M, Cavallini MC, Riboldi C, Bellodi L (2000). Serotonin transporter linked polymorphic region in anorexia nervosa and bulimia nervosa. Mol Psychiatry 5: 233-234; (letter).

Falk CT, Rubinstein P (1987). Haplotype relative risks: an easy reliable way to construct a proper control sample for risk calculations. Ann Hum Genet 51: 227-233.

Fumeron F, Betoulle D, Aubert R, Herbeth B, Siest G, Rigaud D (2001). Association of a functional 5-HT transporter gene polymorphism with anorexia nervosa and food intake. Mol Psychiatry 6: 9-10; (letter).

Gelernter J, Cubells JF, Kidd JR, Pakstis AJ, Kidd KK (1999). Population studies of polymorphisms of the serotonin transporter protein gene. Am J Med Genet 88: 61-66.

Gelernter J, Kranzler H, Cubells JF, Ichinose H, Nagatsu T (1998). DRD2 allele frequencies and linkage disequilibria, including the 
-141CIns/Del promoter polymorphism, in European-American, African-American, and Japanese subjects. Genomics 51: 21-26.

Greenwood TA, Alexander M, Keck PE, McElroy S, Sadovnick AD, Remick RA et al (2002). Segmental linkage disequilibrium within the dopamine transporter gene. Mol Psychiatry 7: 165-173.

Harvey PWJ, Althaus M (1993). The distribution of body mass index in Australian children aged 7-15 years. Aust J Nutr Diet 50: 151-153.

Heils A, Teufel A, Petri S, Stöber G, Riederer P, Bengel D et al (1996). Allelic variation of human serotonin transporter gene expression. J Neurochem 66: 2621-2624.

Hinney A, Barth N, Ziegler A, von Prittwitz S, Hamann A, Hennighausen K et al (1997). Serotonin transporter gene-linked polymorphic region: allele distributions in relationship to body weight and in anorexia nervosa. Life Sci 61: PL295-PL303.

Holland AJ, Sicotte N, Treasure J (1988). Anorexia nervosa: evidence for a genetic basis. J Psychosom Res 32: 561-571.

Jorm AF, Henderson AS, Jacomb PA, Christensen H, Korten AE, Rodgers B et al (1998). An association study of a functional polymorphism of the serotonin transporter gene with personality and psychiatric symptoms. Mol Psychiatry 3: 449-451.

Kaye WH, Gwirtsman HE, George DT, Ebert MH (1991a). Altered serotonin activity in anorexia nervosa after long-term weight restoration. Does elevated cerebrospinal fluid 5-hydroxyindoleacetic acid level correlate with rigid and obsessive behavior? Arch Gen Psychiatry 48: 556-562.

Kaye WH, Jimerson DC, Lake CR, Ebert MH (1985). Altered norepinephrine metabolism following long-term weight recovery in patients with anorexia nervosa. Psychiatry Res 14: 333-342.

Kaye WH, Nagata T, Weltzin TE, Hsu LKG, Sokol MS, McConaha C et al (2001). Double-blind placebo-controlled administration of fluoxetine in restricting- and restricting-purging-type anorexia nervosa. Biol Psychiatry 49: 644-652.

Kaye WH, Weltzin TE, Hsu LKG, Bulik CM (1991b). An open trial of fluoxetine in patients with anorexia nervosa. J Clin Psychiatry 52: 464-471.

Kim SJ, Cox N, Courchesne R, Lord C, Corsello C, Akshoomoff N et al (2002). Transmission disequilibrium mapping at the serotonin transporter gene (SLC6A4) region in autistic disorder. Mol Psychiatry 7: 278-288.

Lesch KP, Bengel D, Heils A, Sabol SZ, Greenberg BD, Petri S et al (1996). Association of anxiety-related traits with a polymorphism in the serotonin transporter gene regulatory region. Science 274: 1527-1531.

Lovejoy EA, Scott AC, Fiskerstrand CE, Bubb VJ, Quinn JP (2003). The serotonin transporter intronic VNTR enhancer correlated with a predisposition to affective disorders has distinct regulatory elements within the domain based on the primary DNA sequence of the repeat unit. Eur J Neurosci 17: 417-420.
Merril CR, Goldman D, Sedman SA, Ebert MH (1981). Ultrasensitive stain for proteins in polyacrylamide gels shows regional variation in cerebrospinal fluid proteins. Science 211: 1437-1438.

Miller SA, Dykes DD, Polesky HF (1988). A simple salting out procedure for extracting DNA from human nucleated cells. Nucleic Acids Res 16: 1215-1215.

Nakamura M, Ueno S, Sano A, Tanabe H (2000). The human serotonin transporter gene linked polymorphism (5-HTTLPR) shows ten novel allelic variants. Mol Psychiatry 5: 32-38.

Pirke KM, Kellner M, Philipp E, Laessle R, Krieg JC, Fichter MM (1992). Plasma norepinephrine after a standardized test meal in acute and remitted patients with anorexia nervosa and in healthy controls. Biol Psychiatry 31: 1074-1077.

Ramamoorthy S, Bauman AL, Moore KR, Han H, Yang-Feng T, Chang AS et al (1993). Antidepressant- and cocaine-sensitive human serotonin transporter: molecular cloning, expression, and chromosomal localization. Proc Natl Acad Sci USA 90: 25422546.

Ricca V, Mannucci E, Paionni A, Di Bernardo M, Cellini M, Cabras PL et al (1999). Venlafaxine versus fluoxetine in the treatment of atypical anorectic outpatients: a preliminary study. Eat Weight Disord 4: 10-14.

Risch N, Merikangas K (1996). The future of genetic studies of complex human diseases. Science 273: 1516-1517.

Ritchie MD, Hahn LW, Roodi N, Bailey LR, Dupont WD, Parl FF et al (2001). Multifactor-dimensionality reduction reveals highorder interactions among estrogen-metabolism genes in sporadic breast cancer. Am J Hum Genet 69: 138-147.

Spielman RS, McGinnis RE, Ewens WJ (1993). Transmission test for linkage disequilibrium: the insulin gene region and insulindependent diabetes mellitus (IDDM). Am J Hum Genet 52: 506516.

Strober M, Freeman R, Lampert C, Diamond J, Kaye W (2000). Controlled family study of anorexia nervosa and bulimia nervosa: evidence of shared liability and transmission of partial syndromes. Am J Psychiatry 157: 393-401.

Sundaramurthy D, Pieri LF, Gape H, Markham AF, Campbell DA (2000). Analysis of the serotonin transporter gene linked polymorphism (5-HTTLPR) in anorexia nervosa. Am J Med Genet 96: 53-55.

Terwilliger JD, Ott J (1992). A haplotype-based 'haplotype relative risk' approach to detecting allelic associations. Hum Hered 42: 337-346.

Urwin RE, Bennetts B, Wilcken B, Lampropoulos B, Beumont P, Clarke $S$ et al (2002). Anorexia nervosa (restrictive subtype) is associated with a polymorphism in the novel norepinephrine transporter gene promoter polymorphic region. Mol Psychiatry 7: 652-657.

WHO (1992). The ICD-10 Classification of Mental and Behavioral Disorders-Clinical Descriptions and Diagnostic Guidelines. WHO: Geneva. pp 176-177. 